\title{
Optimizing Efficacy of New Postharvest Fungicides and Evaluation of Sanitizing Agents for Managing Citrus Green Mold
}

Loukas Kanetis, Department of Plant Pathology, University of California, Riverside 92521; Helga Förster, Department of Plant Pathology, University of California, Davis 95616; and James E. Adaskaveg, Department of Plant Pathology, University of California, Riverside

\begin{abstract}
Kanetis, L., Förster, H., and Adaskaveg, J. E. 2008. Optimizing efficacy of new postharvest fungicides and evaluation of sanitizing agents for managing citrus green mold. Plant Dis. 92:261269.

Three new fungicides, azoxystrobin, fludioxonil, and pyrimethanil, that belong to different chemical classes are highly effective in managing citrus green mold and are being registered for postharvest use in the United States. Recirculating in-line drenches provided a significantly improved efficacy compared with standard low-volume spray applications. To prevent pathogen contamination of drench solutions, two oxidizing disinfectants, sodium hypochlorite and hydrogen peroxide/peroxyacetic acid (HPPA) solutions, were evaluated. Inhibition of conidial germination of Penicillium digitatum was dependent on the $\mathrm{pH}$ of the solution and the exposure time for each sanitizing agent. Chlorine $(50 \mathrm{mg} / \mathrm{liter})$ and HPPA $(2,700 \mathrm{mg} / \mathrm{liter})$ effectively inhibited germination in 40- and 240-s exposures, respectively, at $\mathrm{pH} 7$. All fungicides tested were compatible and effective with HPPA, whereas fludioxonil, azoxystrobin, and thiabendazole, but not imazalil and pyrimethanil, were compatible with chlorine. In laboratory studies, sodium bicarbonate (SBC, $3 \%$ ) significantly increased the efficacy of the three fungicides $(250 \mathrm{mg} / \mathrm{liter})$ and had no adverse effect on their stability in aqueous solutions. Fludioxonil (300 mg/liter)-SBC mixtures were still highly effective when applied $24 \mathrm{~h}$ after fruit inoculation. In experimental packingline studies, SBC or SBC-chlorine improved the efficacy of fludioxonil, whereas azoxystrobin was effective with and without these additives. Heating of drench solutions of fludioxonil $(300 \mathrm{mg} / \mathrm{liter})$ to $50^{\circ} \mathrm{C}$ did not improve decay control. In conclusion, in-line recirculating drench applications and fungicide-sanitizer-SBC mixtures significantly increased fungicide efficacy and provide an integrated approach for optimizing fungicide efficacy. These strategies also should minimize the selection for resistant isolates of the pathogen.
\end{abstract}

Additional keyword: sanitation

Green mold caused by Penicillium digitatum (Pers.) Sacc. is the most important postharvest decay of citrus fruit. In California and other citrus production areas, postharvest fungicide treatments are an integral part of the management of green mold. In contrast to other fresh fruit commodities in California, citrus fruit are harvested, stored, and processed almost yearround. Because inoculum is continuously present and reintroduced, decay management in packinghouses is a challenging task. Sodium ortho-phenylphenate, thiabendazole (TBZ), and imazalil have been available for postharvest use for many years, but resistance to these fungicides is very common (5). Currently, three new fungicides, azoxystrobin, fludioxonil, and pyrimethanil, are being introduced in the United States that all are highly effective

Corresponding author: J. E. Adaskaveg

E-mail: jim.adaskaveg@ucr.edu

Accepted for publication 19 September 2007.

doi:10.1094/PDIS-92-2-0261

(C) 2008 The American Phytopathological Society in reducing the incidence of green mold but differ in their post-infection efficacy and antisporulation activity $(2,15)$. Thus, when aqueous fungicide solutions were applied 9 to $21 \mathrm{~h}$ after inoculation, pyrimethanil provided the highest level of green mold decay control, whereas the efficacy of fludioxonil and azoxystrobin was very high at the early timings but diminished as application time after inoculation increased. Pyrimethanil, however, was less effective in inhibiting sporulation of the pathogen. In addition, azoxystrobinfludioxonil mixtures were significantly more effective than single-fungicide treatments.

To maximize the performance of postharvest treatments, various approaches have been used previously that sometimes significantly increased treatment efficacy. Thus, for citrus fruit, the addition of sodium bicarbonate (SBC) increased treatment performance in green mold decay management compared with the use of TBZ or imazalil alone $(25,27)$. Furthermore, solutions of TBZ or imazalil heated to 41 or $50^{\circ} \mathrm{C}$ resulted in an improved efficacy $(7,27)$. Newer fungicides such as fludioxonil and pyrimethanil recently have been evaluated as heated treatments (7,22,23,26). Recirculating, in-line drench applications to inoculated plum fruit were shown to reduce decay incidence significantly compared with in-line, low-volume spray applications (12). These strategies also need to be evaluated for the three new postharvest fungicides for citrus fruit. In addition, sanitizing treatments that can be used in recirculating fungicide solutions have to be evaluated for their interaction with fungicide efficacy. Because recirculating fungicide solutions are being used for an extended time period, the build-up of microbial populations has to be prevented to avoid contamination of healthy fruit and to minimize selection of fungicide-resistant pathogen propagules.

Thus, the objectives of this study were to (i) compare the efficacy of azoxystrobin, fludioxonil, and pyrimethanil in reducing green mold of lemon fruit using different postharvest application methods; (ii) compare the effect of the sanitizing agents sodium hypochlorite and hydrogen peroxide/peroxyacetic acid (HPPA) on viability of conidia of $P$. digitatum in regard to exposure time and $\mathrm{pH}$ of the solutions; (iii) determine interactions of SBC and sanitizing agents on the stability and efficacy of citrus postharvest fungicides; and (iv) determine the efficacy of nonheated and heated solutions of fludioxonil and fludioxonil-SBC.

\section{MATERIALS AND METHODS}

Fungal isolates. Two single-spore isolates of $P$. digitatum were used in the studies. Isolate Pd was sensitive to imazalil and TBZ (50\% effective concentration $\left[\mathrm{EC}_{50}\right]$ values for mycelial growth $=0.05$ and 0.08 $\mathrm{mg} /$ liter, respectively), whereas isolate 2152 was resistant to both fungicides $\left(\mathrm{EC}_{50}\right.$ values $=0.65$ and $>7.82 \mathrm{mg} / \mathrm{liter}$, respectively). Isolates were maintained as mycelial plugs in sterile water at $4^{\circ} \mathrm{C}$ for up to 1 year. For conidial production, isolates were grown on potato dextrose agar (PDA) (Difco Laboratories, Detroit, MI) and incubated at $25^{\circ} \mathrm{C}$ for 5 to 10 days. Spore suspensions were prepared in $0.01 \%$ Tween 20 (Sigma-Aldrich, St. Louis, MO) and adjusted to the appropriate concentrations with sterile water using a hemacytometer.

Fungicides and sanitation agents. Fungicides used were formulated products of azoxystrobin (Abound 2.08F; Syngenta 
Crop Protection, Greensboro, NC), fludioxonil (Scholar 50WP; Syngenta Crop Protection), imazalil (Freshgard 700; Janssen Pharmaceutica, Titusville, NJ), pyrimethanil (Penbotec 400SC; Janssen Pharmaceutica), and thiabendazole (Decco Salt No. 19; Decco-Cerexagri, Monrovia, CA). Standard solutions of fungicides for gas chromatography were prepared using technical-grade materials that were supplied by the manufacturers. Sodium bicarbonate (Arm and Hammer; Church and Dwight Co. Inc., Princeton, NJ) and the sanitizing agents sodium hypochlorite (household bleach containing approximately $5.25 \% \mathrm{NaOCl}$ ) and commercial HPPA (ZeroTol, 27\% hydrogen peroxide; BioSafe Systems, Glastonbury, CT) were used alone or in combination with fungicides. All concentrations were based on the active ingredient of each chemical.

Effect of application method on fungicide efficacy in reducing citrus green mold. Lemon fruit (Citrus limon (L.) N.L. Burm.) cv. Eureka were used in fruit inoculation studies. Fruit for the laboratory studies were obtained from a research orchard at the University of California, Riverside; whereas, for the experimental packingline studies, freshly picked fruit were obtained from local packinghouses. Lemon fruit used in these studies were not treated with preharvest fungicides and were randomized for each experiment based on size and maturity. The flavedo and albedo of lemon fruit were punctured (one 1-by-2-mm wound per fruit) with a nail-like, stainless-steel probe without injuring the juice sacks below the albedo. For inoculation, a 20- $\mu$ l drop of inoculum $\left(10^{6}\right.$ spores $\left./ \mathrm{ml}\right)$ from the imazalil- and TBZ-resistant isolate of $P$. digitatum was placed on each wound. Inoculated fruit were placed into fruit trays in cardboard fruit boxes that were covered with plastic bags and incubated at $20^{\circ} \mathrm{C}$ for 12 to $14 \mathrm{~h}$. Postharvest fungicide treatments were conducted on an experimental packingline at the University of California Kearney Agricultural Center, Parlier. High-volume, in-line drenches were applied to lemon fruit by pumping a fungicide solution from a 70liter reservoir above a perforated steel distribution pan (91-by-91-cm area with 127 5mm-diameter holes evenly distributed) approximately $16 \mathrm{~cm}$ over a moving roller bed. Fungicides were used at $500 \mathrm{mg} / \mathrm{liter}$ and treatment volumes were equivalent to 33 liters per 10,000 kg of fruit. Fungicide treatments were followed by a low-volume spray application with a 1:10 dilution ( $\mathrm{vol} / \mathrm{vol}$ ) of a storage fruit coating (PacRite 505-35; Pace International, Seattle, WA) using a controlled droplet applicator (CDA; Decco-Cerexagri) that was positioned in the center of the treatment area and approximately $20 \mathrm{~cm}$ above the roller bed. Treatment volumes for the spray applications of fruit coatings were adjusted to 8.3 liters per $10,000 \mathrm{~kg}$ of fruit by regulating fruit coating output volumes and speed of fruit movement through the treatment area. Lowvolume fungicide treatments were applied in the diluted storage fruit coating over either a roller bed or a horse-hair brush bed using the same specifications as above for the fruit-coating applications with fungicide rates of $4,000 \mathrm{mg} /$ liter. Based on these rates and treatment volumes, low-volume spray applications were done at twice the rate compared with the in-line drench applications (i.e., $33.2 \mathrm{~g}$ per $10,000 \mathrm{~kg}$ of fruit for the spray applications). Treatment times for all application methods were generally between 12 and $15 \mathrm{~s}$. Control fruit were treated only with water and fruit coating in each of the three application methods. Between treatments, fungicide reservoirs and tubing, as well as treatment beds, were cleaned with a commercial alkaline detergent (PacFoam Plus; Pace International) and then thoroughly rinsed with water. Fruit then were incubated in fruit boxes for 6 to 7 days at $20^{\circ} \mathrm{C}$. Treatments were randomized among boxes and boxes were covered with plastic bags. For evaluation, fruit were inspected carefully for green mold development that was either easily visible as mycelium- or conidia-covered decay or present as soft, often watery lesions around the inoculation site. Decay incidence was based on the number of decayed fruit of the total number of fruit inoculated. There were four replications of 24 fruit for each treatment and the experiment was done twice. To determine the standardized improved efficacy in the comparisons of fungicide application methods for each fungicide and application method, the incidence of decay first was subtracted from that of the appropriate control. This value then was calculated as a percentage of the incidence of the control treatment (i.e., the standardized efficacy). The standardized improved efficacy was determined by subtracting the incidence of decay of the least effective method from that of each of the other two methods.

Effect of sanitizing agents on viability of $\boldsymbol{P}$. digitatum conidia. In laboratory studies, the efficacy of HPPA was compared with that of sodium hypochlorite (prepared from commercial household bleach) using selected exposure times and acidities of the test solutions. Dilutions of both sanitizing agents at selected $\mathrm{pH}$ values were prepared in sterile distilled water with HPPA at 3,000 mg/liter (based on hydrogen peroxide) and free chlorine ( $\mathrm{HOCl}$ and $\left.\mathrm{OCl}^{-}\right)$at $55.5 \mathrm{mg} /$ liter. The concentration of free chlorine was verified using autodilution ampoules for the colorimetric analysis of chlorine (Vacuettes R-2505D; Chemetrics, Inc., Calverton, VA). The acidity of the test solutions was adjusted to $\mathrm{pH} 6,7$, and 8 using $0.1 \mathrm{~N}$ sodium hydroxide for HPPA and $1 \mathrm{~N}$ hydrochloric acid for sodium hypochlorite. For testing the effect on viability of conidia, $1 \mathrm{ml}$ of conidial suspension $\left(5 \times 10^{7}\right.$ conidia/ml $)$ of the imazalil- and
TBZ-resistant isolate of $P$. digitatum was pipetted into sterile glass test tubes containing $9 \mathrm{ml}$ of the test solutions, resulting in final concentrations of $2,700 \mathrm{mg} / \mathrm{liter}$ for hydrogen peroxide and $50 \mathrm{mg} /$ liter for free chlorine. Control tubes contained $9 \mathrm{ml}$ of sterile distilled water. Tubes were vortexed and, after selected times $(30,60$, 120 , and $240 \mathrm{~s}$ for HPPA; 10, 20, 40, and $60 \mathrm{~s}$ for free chlorine), reactions were stopped by adding $2 \mu \mathrm{l}$ of each reaction mixture to $1.998 \mathrm{ml}$ of sterile water in microcentrifuge tubes, thus diluting the sanitizing agents 1,000 times. For each reaction mixture, three $20-\mu \mathrm{l}$ drops then were placed onto PDA in petri dishes. After incubation for 16 to $18 \mathrm{~h}$ at $25^{\circ} \mathrm{C}$, viability of conidia was assessed based on conidial germination. Using an inverted microscope (Axiovert S100; Zeiss, Germany), 50 conidia in each drop were evaluated for germination. Results were expressed as percent of germinated conidia of the total conidia evaluated. This experiment was performed three times.

Stability of citrus postharvest fungicides in the presence of sanitizing agents and SBC. Concentrations of fludioxonil, pyrimethanil, imazalil, and TBZ were determined by gas chromatography after incubation in solutions of HPPA, sodium hypochlorite, or mixtures of sodium hypochlorite with SBC. For this, fungicide solutions (each fungicide at $100 \mathrm{mg} / \mathrm{liter}$ ) were prepared without and with the addition of free chlorine at $100 \mathrm{mg} / \mathrm{liter}$, HPPA at $2,700 \mathrm{mg} /$ liter (based on hydrogen peroxide), or a mixture of free chlorine at 100 $\mathrm{mg} / \mathrm{liter}$ and $3 \%$ (wt/vol) SBC. After 0.5 and $8 \mathrm{~h}$ at $25^{\circ} \mathrm{C}$, fungicide concentrations were determined using a gas chromatograph (Model 5890 GC; Agilent, Santa Clara, CA) equipped with an autosampler, an autoinjector, a nitrogen-phosphorus detector, and a Zebron ZB-35 capillary GC column ( $15 \mathrm{~m}$ long by $0.53-\mathrm{mm}$ inner diameter). The following conditions were used: $300^{\circ} \mathrm{C}$ injection port temperature, $350^{\circ} \mathrm{C}$ detector temperature, $200^{\circ} \mathrm{C}$ initial temperature, and $260^{\circ} \mathrm{C}$ final temperature. Temperature ramping was $10^{\circ} \mathrm{C} / \mathrm{min}$. Calibration was done using fungicide standards of $0.5,1,2$, and $5 \mu \mathrm{g} / \mathrm{ml}$ that were prepared from technical-grade material. Fungicide concentrations were compared with the controls (initial concentration of the fungicides when mixed in water). This experiment was performed twice.

Effect of sanitizing agents on the efficacy of postharvest fungicides in reducing citrus green mold. In laboratory studies, aqueous solutions of azoxystrobin, fludioxonil, and pyrimethanil $(250 \mathrm{mg} / \mathrm{liter}$ each) were prepared immediately before ( 0 h) or $8 \mathrm{~h}$ before use either without additives or with the addition of free chlorine at $100 \mathrm{mg} /$ liter, hydrogen peroxide at $2,700 \mathrm{mg} /$ liter, $100 \mathrm{mg}$ of free chlorine + $3 \%(\mathrm{wt} / \mathrm{vol}) \mathrm{SBC}$, or hydrogen peroxide at $2,700 \mathrm{mg} / \mathrm{liter}+3 \%(\mathrm{wt} / \mathrm{vol}) \mathrm{SBC}$. Lemon 
fruit were inoculated with the imazalil- and TBZ-resistant isolate of $P$. digitatum, incubated at $20^{\circ} \mathrm{C}$ for 14 to $16 \mathrm{~h}$, and then treated with the above solutions (10 liters) by dipping for $30 \mathrm{~s}$. Treated fruit were allowed to air dry, incubated at $20^{\circ} \mathrm{C}$, and evaluated for decay development as described above. The experiment was performed twice, with four replications per treatment and 12 fruit per replication.

Efficacy of nonheated and heated solutions of fludioxonil and of mixtures of fludioxonil or azoxystrobin with SBC and chlorine in reducing citrus green mold. The efficacy of fludioxonil, SBC, and fludioxonil-SBC mixtures was evaluated in laboratory studies. The effect of heated treatments of fludioxonil and the addition of SBC or SBC-chlorine to fludioxonil or azoxystrobin solutions for controlling green mold was evaluated in experimental packingline studies. In laboratory studies, lemon fruit were inoculated with the imazalil- and TBZ-resistant isolate of $P$. digitatum as described above and treated after 14 or $24 \mathrm{~h}$ using sprays of aqueous solutions of fludioxonil (300 $\mathrm{mg} / \mathrm{liter}$ ), 3\% (wt/vol) SBC, or a mixture of these two materials at the same concentrations. Sprays were applied using an atomizer (Model 15-RD; DeVilbiss Health Care, Somerset, PA) at approximately 8.3 liters per $10,000 \mathrm{~kg}$ of fruit $(0.5 \mathrm{ml} /$ fruit $)$. For the packingline studies, fruit in the repeated experiments were inoculated with the imazalil- and TBZ-resistant or -sensitive isolates and treated after 12 to $15 \mathrm{~h}$ using aqueous in-line drenches as described above for the following treatments: fludioxonil at $300 \mathrm{mg} / \mathrm{liter}$, azoxystrobin at 500 $\mathrm{mg} / \mathrm{liter}$, and mixtures of each fungicide with 3\% (wt/vol) SBC or SBC plus free chlorine at $50 \mathrm{mg} / \mathrm{liter}$. Drench solutions for fludioxonil were held at ambient temperature $\left(25^{\circ} \mathrm{C}\right)$ or were heated to $50^{\circ} \mathrm{C}$ and fruit to be treated were adjusted to $25^{\circ} \mathrm{C}$. Between replications of heated treatments, temperatures were readjusted to $50^{\circ} \mathrm{C}$. The $\mathrm{pH}$ of the aqueous fungicide solutions was 6.5 to 7 , whereas the fungicide-SBC mixtures had a $\mathrm{pH}$ of 8 to 8.5 . Fungicide drench treatments were followed by low-volume spray applications with diluted storage fruit coating, and fruit then were incubated, stored, and evaluated as described above. For each of the four replications, 12 fruit were used in the laboratory studies and 24 fruit in the packingline studies, and experiments were conducted twice.

Statistical analysis of data. Percentage data were arcsine transformed. Bartlett's test for homogeneity of variances was performed for repeated experiments. Data sets with homogeneous variances $(P<$ $0.05)$ were combined and then analyzed using a one-, two-, or three-way classification of data depending on the experiment. In experiments with multiple comparisons, a balanced factorial design was used for treatment comparisons. For error control, all treatments were in a randomized complete-block design. Values were analyzed using general linear model or analysis of (LSD) mean separation procedures of SAS (version 9.1; SAS Institute, Cary, NC).

\section{RESULTS}

Effect of application method on fungicide efficacy in reducing citrus green mold. The efficacy of azoxystrobin, fludioxonil, and pyrimethanil against green mold of lemon fruit was compared using low-volume spray applications over roller or brush treatment beds and high-volume, recirculated, in-line drench applications. These studies resulted in highly significant $(P<0.01)$ differences between treatment methods. In addition, there was a highly significant interaction $(P<0.01)$ between fungicide and application method, indicating that fungicides performed differently using the three methods. Thus, data in Figure 1 are presented separately for each fungicide. As indicated in these comparisons, for all three fungicides the highvolume, in-line drenches were significantly more effective than the low-volume spray applications (CDA). There was, however, no significant difference in efficacy whether low-volume sprays were done over a roller or a brush treatment bed. Effectiveness of azoxystrobin and fludioxonil was increased by 15 and $25 \%$, respectively, when applied using an in-line drench compared with the spray application over a roller bed. For pyrimethanil, the efficacy variance and least significant difference

was improved by $15.7 \%$ compared with the spray application over a brush bed (Fig. 1).

Effect of sanitizing agents on viability of $\boldsymbol{P}$. digitatum conidia. The effect of chlorine and HPPA on the viability of conidia of $P$. digitatum was evaluated for different exposure times and pHs. For both sanitizers, solutions at $\mathrm{pH} 6$ and 7 were significantly $(P<0.01)$ more effective in killing conidia than solutions at $\mathrm{pH} 8$. Because a significant interaction $(P<0.01)$ occurred between $\mathrm{pH}$ and exposure time, comparisons of exposure times of each sanitizer then were done for each $\mathrm{pH}$ value.

Exposures in solutions of free chlorine at $50 \mathrm{mg} /$ liter for $10 \mathrm{~s}$ at $\mathrm{pH} 6,7$, or 8 reduced conidial germination to 5.6, 11.7, and $35.1 \%$, respectively, compared with $>95 \%$ germination in the water control (Fig. 2A). Less than $1 \%$ of the conidia germinated after 20 - or 40 -s exposures at pH 6 and 7, respectively; whereas, after a 60-s exposure at $\mathrm{pH} 8,5.5 \%$ of the conidia still germinated. For HPPA, higher concentrations and longer exposure times were required to reduce viability of $P$. digitatum conidia compared with chlorine. At $\mathrm{pH} 6$ and 7, 240-s exposures resulted in no germination whereas, at $\mathrm{pH} 8,6.9 \%$ of the conidia were still viable compared with $>95 \%$ germination in the water control (Fig. 2B). At pH 5, the acidity level of a nonadjusted aqueous dilution of HPPA, no germination was observed after a 120-s exposure (data not shown).

Stability of citrus postharvest fungicides in the presence of sanitizing agents

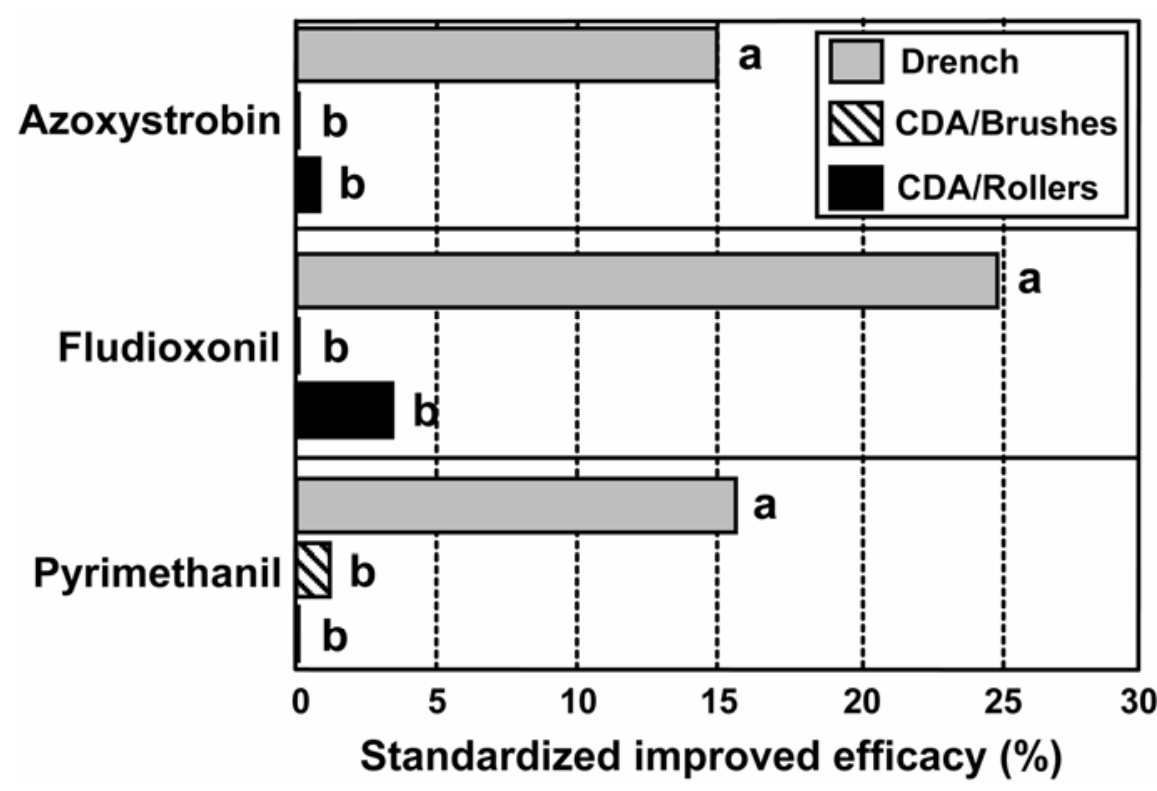

Fig. 1. Comparative efficacy of postharvest fungicides against green mold of lemon fruit using three application methods. In the low-volume sprays, fungicides at 4,000 mg/liter were applied in diluted storage fruit coating using a controlled droplet applicator (CDA) that was positioned over either a brush or roller treatment bed. In the in-line drench applications, aqueous fungicide applications at 500 $\mathrm{mg} / \mathrm{liter}$ were followed by a low-volume spray application with diluted storage fruit coating. For each fungicide, a standardized improved efficacy was calculated (as indicated in the Materials and Methods) and horizontal bars with the same letter indicate that treatment means were not significantly different $(P<0.05)$ following an analysis of general linear models and least significant difference mean separation test procedures. 
and SBC. The stability of fludioxonil, pyrimethanil, imazalil, and TBZ in solutions of HPPA (hydrogen peroxide at 2,700 $\mathrm{mg} /$ liter $)$, free chlorine (100 $\mathrm{mg} / \mathrm{liter})$, or mixtures of SBC (3\%) and free chlorine ( $100 \mathrm{mg} /$ liter) was evaluated after 0.5 - and 8-h incubations using gas chromatography. Both fludioxonil and TBZ were stable in the three sanitizing solutions, as indicated by the presence of fungicide residues in the solutions similar to the controls (i.e., the initial concentration of the fungicides when mixed in water; Fig. 3). In addition, concentrations of both fungicides remained quite stable for 7 days after preparation (data not shown). At this time, a 7.5\% decrease in fungicide concentration was observed only in solutions containing both chlorine and 3\% SBC. Pyrimethanil and imazalil also were found to be stable in HPPA but not in chlorine or chlorine-SBC. After 0.5 and $8 \mathrm{~h}$ of exposure in chlorine, the pyrimethanil concentration was reduced to 60 and $45 \%$ and the imazalil concentration was reduced to 90 and $5 \%$, respectively, of the water control. Degradation of these fungicides in chlorine-SBC mixtures was significantly higher in some cases than in chlorine alone. Thus, after 0.5 and $8 \mathrm{~h}$ of exposure, the pyrimethanil concentration was reduced to 40 and $17.5 \%$ and the imazalil concentration was reduced to 35 and $5 \%$, respectively, compared with the water control (Fig. 3).

Effect of sanitizing agents on the efficacy of postharvest fungicides in reducing citrus green mold. The stability of azoxystrobin, fludioxonil, and pyrimetha-
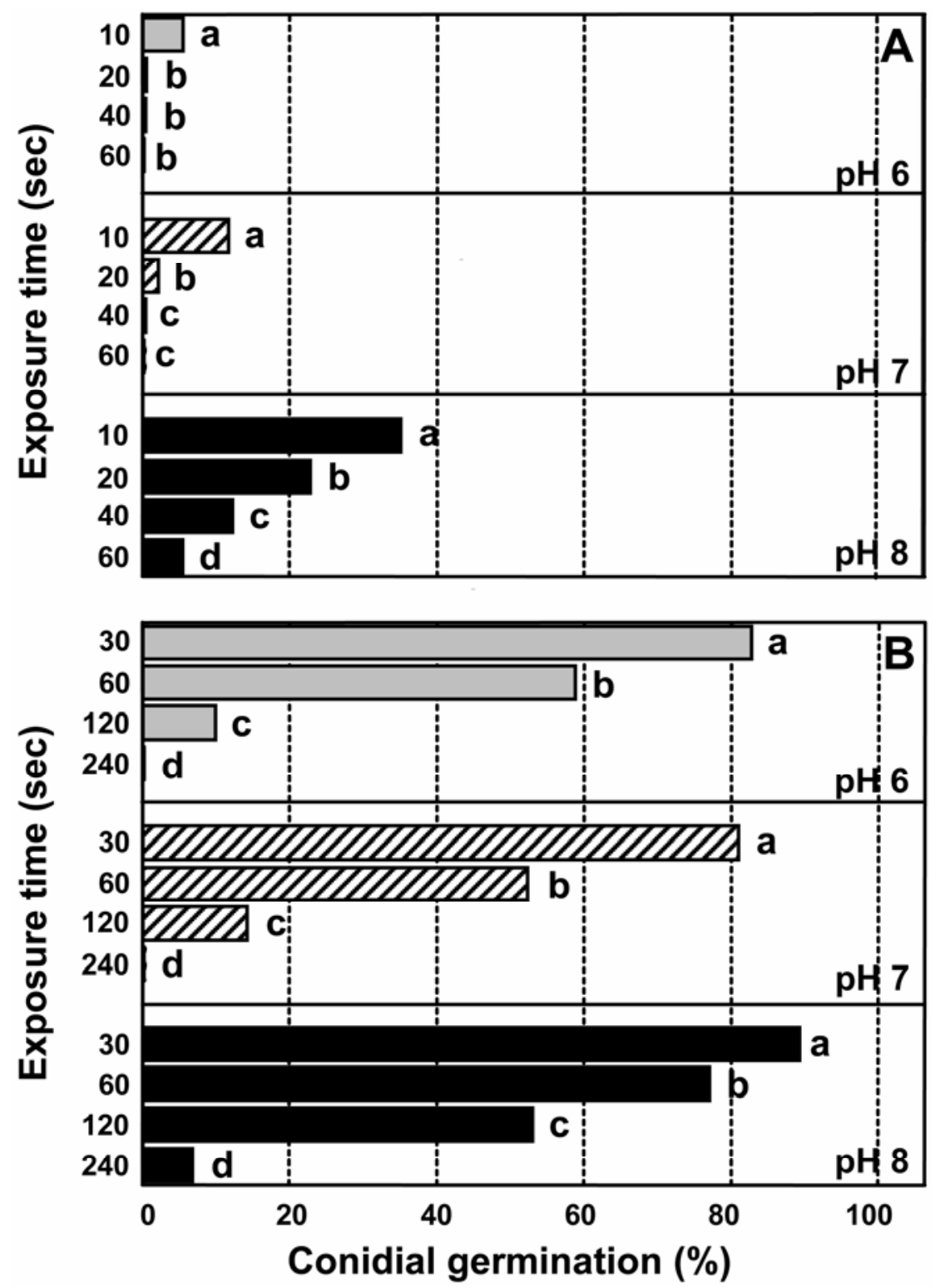

Fig. 2. In vitro effect of chlorine and a mixture of hydrogen peroxide and peroxyacetic acid (HPPA) on viability of conidia of Penicillium digitatum. Conidia were incubated in solutions of $\mathbf{A}$, free chlorine at $50 \mathrm{mg} /$ liter or $\mathbf{B}, 2,700 \mathrm{mg}$ of HPPA (based on the concentration of hydrogen peroxide) at $\mathrm{pH} 6,7$, or 8 for selected times. For each sanitizing agent at a specific $\mathrm{pH}$, horizontal bars with the same letter indicate that treatment means were not significantly different $(P<0.05)$ following an analysis of variance and least significant difference mean separation test procedures.

nil also was evaluated in experiments where fruit were treated 14 to $16 \mathrm{~h}$ after inoculation with fungicide-sanitizer solutions that were prepared either immediately before $(0 \mathrm{~h})$ or $8 \mathrm{~h}$ before treatment. A change in fungicide efficacy from that of the aqueous control solution (i.e., without additives) was considered indicative of a positive or negative reaction between fungicide and sanitizer. For azoxystrobin and fludioxonil, no significant interaction was found between preparation time and treatment efficacy for each fungicide. Thus, data for the two timings were combined in Figure 4A and B. For pyrimethanil, there was a significant interaction between preparation time and fungicide efficacy and, thus, data are presented for each for the two preparation times (Fig. 4C). Using the aqueous fungicide solutions alone at reduced concentrations of $250 \mathrm{mg} / \mathrm{liter}$, decay incidence was $37.5 \%$ for azoxystrobin, $55.0 \%$ for fludioxonil, and 5.5 to $10 \%$ for pyrimethanil compared with $100 \%$ in the untreated control.

For azoxystrobin and fludioxonil, there were no significant differences in decay incidence between aqueous preparations and preparations in free chlorine at 100 mg/liter or HPPA (hydrogen peroxide at $2,700 \mathrm{mg} / \mathrm{liter}$ ), indicating that the two sanitizers did not affect fungicide performance (Fig. 4A and B). Efficacy for both of these fungicides, however, was improved significantly when SBC was added to the sanitizers, as indicated by low levels $(\leq 9.9 \%)$ of decay incidence. For pyrimethanil, at both timings the addition of HPPA or HPPA-SBC resulted in decay levels similar to the aqueous fungicide treatment, indicating no interaction. The efficacy of this fungicide, however, was reduced significantly in solutions containing chlorine in the 0 - and 8-h-old preparations, except when chlorine was mixed with SBC and used immediately after preparation. Thus, decay incidences for the 0 - and 8-h treatments with solutions containing chlorine were 49.5 and $72.4 \%$ and for solutions containing chlorine and SBC were 8.7 and $32.3 \%$, respectively (Fig. 4C).

Efficacy of nonheated and heated solutions of fludioxonil and of mixtures of fludioxonil or azoxystrobin with SBC and chlorine in reducing citrus green mold. In laboratory studies using fludioxonil, SBC, and fludioxonil-SBC mixtures, treatment $(P<0.01)$, treatment timing (14 and $24 \mathrm{~h} ; P<0.02)$, and their interaction $(P<0.01)$ were significant and, thus, treatments were compared for each timing separately (Fig. 5). Both fludioxonil and SBC significantly reduced the incidence of green mold of lemon fruit compared with the untreated control when applied 14 or $24 \mathrm{~h}$ after inoculation with $P$. digitatum (Fig. 5). Treatment efficacy at both timings was increased significantly when fludioxonil-SBC mixtures were used 
compared with the single treatments (i.e., fludioxonil or SBC). Decay incidence in these latter treatments was 5.2 and $10.4 \%$ for the 14- and 24-h timings, respectively, compared with $100 \%$ incidence in the control.

In an experimental packingline study, the efficacy of nonheated $\left(25^{\circ} \mathrm{C}\right)$ and heated $\left(50^{\circ} \mathrm{C}\right)$ drench treatments with fludioxonil and fludioxonil-SBC was evaluated. There were significant $(P<$ 0.01) differences between the treatments but no significant differences between temperatures $(P=0.44)$, and there was no interaction between temperature and fungicide efficacy $(P=0.89)$. As in the laboratory study, the efficacy of fludioxonil was improved significantly when mixed with SBC (Fig. 6A). When applied $14 \mathrm{~h}$ after inoculation, fludioxonil reduced the incidence of decay to $17.7 \%$, whereas the mixture of fludioxonil with SBC or SBCchlorine reduced the incidence to 3.9 and $4.0 \%$, respectively, compared with the nontreated control with $68.1 \%$ decay. Drench applications with azoxystrobin, azoxystrobin-SBC, or azoxystrobin-SBCchlorine reduced decay incidence to 4.2 , 4.2 , or $3.7 \%$, respectively, compared with the nontreated control with $74.8 \%$ decay (Fig. 6B).

\section{DISCUSSION}

Three new postharvest fungicides, azoxystrobin, fludioxonil, and pyrimethanil, are being introduced currently for the management of citrus green mold. Because resistance against the previously registered fungicides is widespread in populations of $P$. digitatum $(5,10)$, the judicious use of the new compounds is critical to ensure their lasting efficacy. For this, the utilization of fungicide mixtures or rotations of fungicides have been suggested if fruit receive more than one treatment, as is done commonly with stored lemon fruit in California (15). In the current study, additional strategies were investigated such as the optimization of fungicide application methods. Furthermore, we evaluated the addition of SBC and sanitation agents to improve fungicide efficacy and to reduce the spread of pathogen inoculum. Thus, the overall aim of this study was to define conditions that provide the highest efficacy of the new postharvest fungicides and address the need of the citrus industry for reliable, integrated green mold management.

Low- and ultra-low-volume in-line fungicide spray applications to wet, washed fruit have been the standard treatment method of the California fruit industries for many years. These treatments are economical and environmentally sound because run-off is limited and, consequently, few disposal problems arise. Low-volume spray applications, however, can have limitations on types of fruit where adequate residues are difficult to achieve. Similar to a previous study with plum fruit (12), comparisons of postharvest application methods in the current study showed that, for all three fungicides evaluated, highvolume, in-line drench applications were significantly more effective in reducing decay of inoculated lemon fruit than lowvolume spray applications. In-line drench applications were superior in performance, although fungicides in the drench applications were used at half rates of the spray applications (as calculated based on fruit weight treated). Thus, fungicide coverage probably is improved using drench applications and fungicide deposition into wound sites may have increased.

Postharvest fungicides commonly have been applied to citrus fruit after harvest as nonrecovery sprays, dips, or foams over brushes or rollers (1). There is currently an increasing trend in the California postharvest citrus industry for the use of recirculating, in-line drench applications. Thus, these applications are proving their practicability in commercial packinghouses. Because fungicide solutions for in-line drenches can be recirculated for extended use, these high-volume applications can still be done economically. By treating only fruit that are washed and sanitized, contamination of the fungicide solutions with pathogen propagules can be minimized.

To reduce the amount of remaining infective inoculum in the fungicide solutions, we evaluated the use of sanitation treatments. For TBZ, chlorine has been used routinely to disinfect postharvest treatment solutions (27). Chlorine and
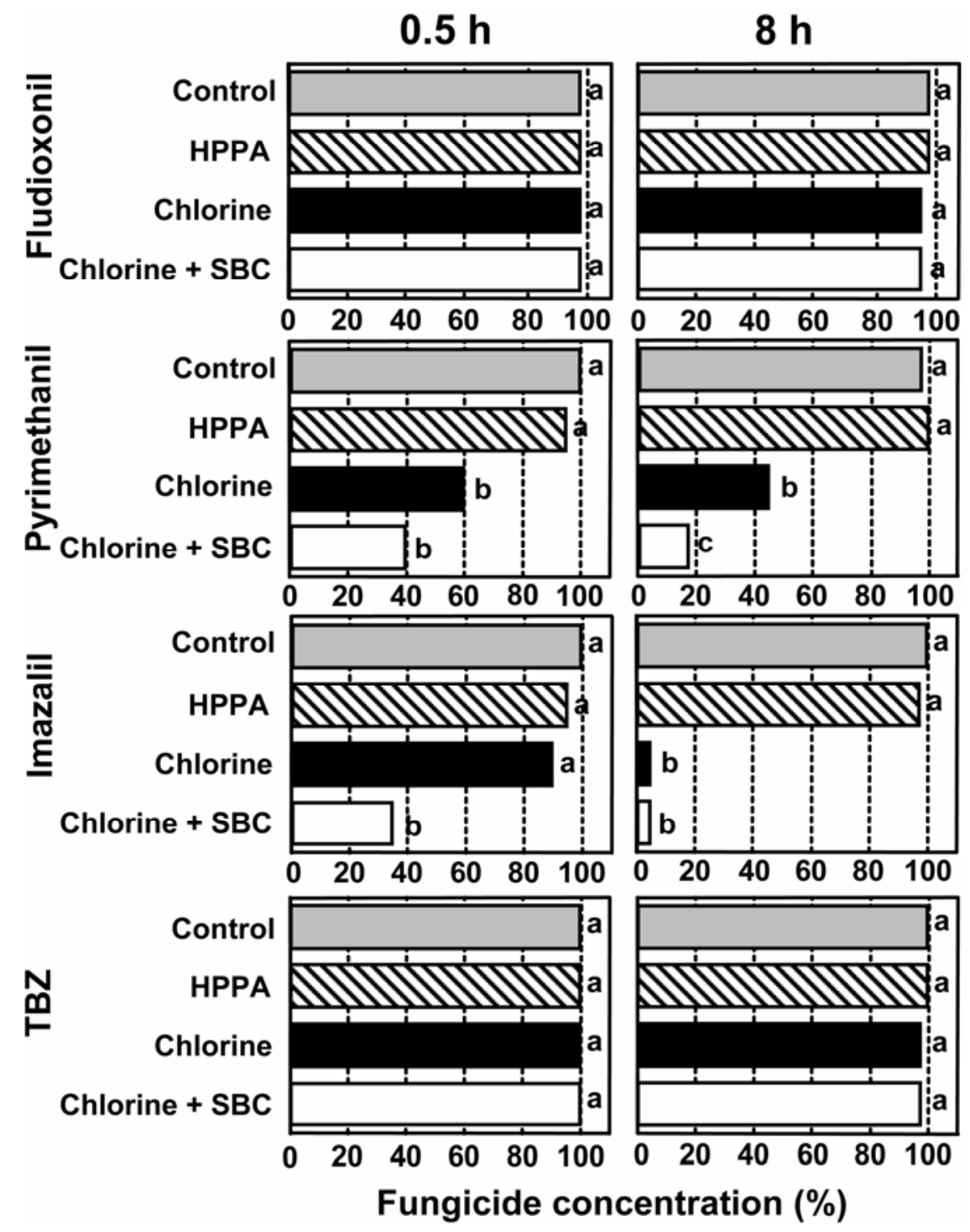

Fig. 3. Effect of sanitizing agents and sodium bicarbonate (SBC) on the stability of citrus postharvest fungicides. $\mathrm{TBZ}=$ thiabendazole. Fungicides (each $100 \mathrm{mg} / \mathrm{liter}$ ) were incubated in solutions of hydrogen peroxide/peroxyacetic acid (HPPA; hydrogen peroxide at 2,700 mg/liter), free chlorine (100 $\mathrm{mg} / \mathrm{liter})$, or mixtures of SBC (3\%, wt/vol) and free chlorine $(100 \mathrm{mg} / \mathrm{liter})$. After 0.5 and $8 \mathrm{~h}$, fungicide concentrations were determined using gas chromatography. For each fungicide and incubation period, horizontal bars with the same letter indicate that treatment means were not significantly different $(P<0.05)$ following an analysis of variance and least significant difference mean separation test procedures. 
HPPA were tested in our studies for their ability to directly inactivate $P$. digitatum conidia, as well as for their interaction with fungicide stability and activity.

Chlorine also is used extensively for sanitation of fruit and equipment in packinghouses. Although very effective, this sanitation agent has several disadvantages. For example, its efficacy is highly dependent on $\mathrm{pH}$, and the presence of organic material can reduce biocidal activity significantly $(4,8,31)$. Moreover, chlorine solutions can cause excessive corrosion to metal equipment $(20,31)$ and health-safety issues can arise due to the potential formation of toxic chlorinated by-products, including chloroform $(8,20,31)$; thus, chlorine use is restricted or prohibited under current organic production program rules of the Organic Materials Review Institute (OMRI).
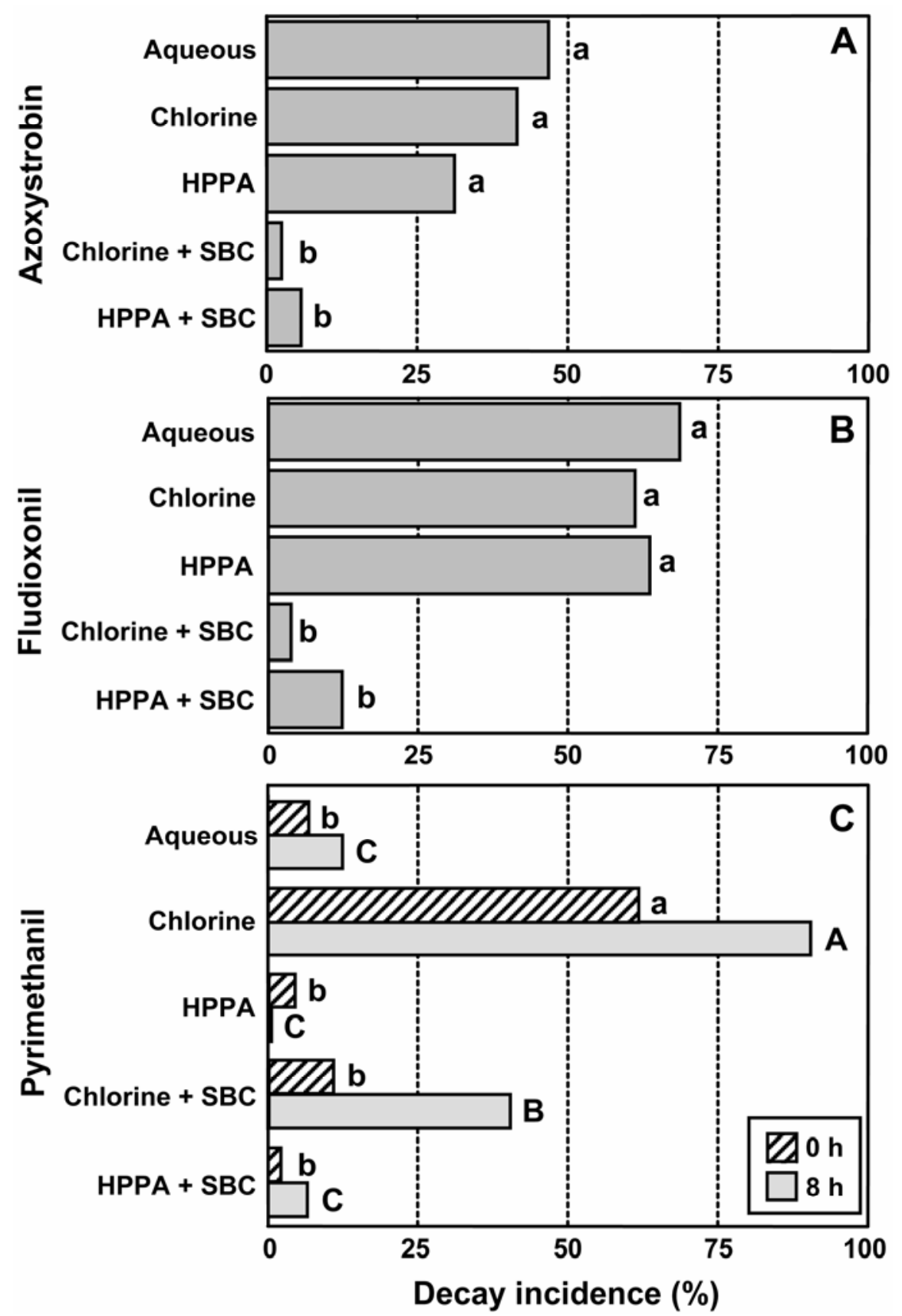

Fig. 4. Effect of sanitizing agents and sodium bicarbonate (SBC) on the efficacy of citrus postharvest fungicides to control green mold of lemon fruit in laboratory studies. Inoculated fruit were treated after 14 to $16 \mathrm{~h}$ with aqueous solutions of A, azoxystrobin, $\mathbf{B}$, fludioxonil, or $\mathbf{C}$, pyrimethanil ( $250 \mathrm{mg} / \mathrm{liter}$ each). Solutions were prepared either immediately before use $(0 \mathrm{~h})$ or $8 \mathrm{~h}$ before use without additives, or with the addition of free chlorine at $100 \mathrm{mg} /$ liter, hydrogen peroxide at $2,700 \mathrm{mg} /$ liter (using a hydrogen peroxide-peroxyacetic acid mixture [HPPA]), $100 \mathrm{mg}$ of free chlorine $+3 \%(\mathrm{wt} / \mathrm{vol}) \mathrm{SBC}$, or hydrogen peroxide at $2,700 \mathrm{mg} / \mathrm{liter}+3 \% \mathrm{SBC}$. For azoxystrobin and fludioxonil, no significant differences between freshly prepared and 8 -h-old solutions were found and data were combined. For each fungicide, horizontal bars with the same letter (for pyrimethanil, lowercase for $0 \mathrm{~h}$ and uppercase for 8 h) indicate that treatment means were not significantly different $(P<0.05)$ following an analysis of variance and least significant difference mean separation test procedures.

Following Environmental Protection Agency and Food and Drug Administration regulations toward tighter restrictions regarding health safety and environmental concerns, new sanitizers are being developed for use in the food industry. Hydrogen peroxide and peroxyacetic acid are two biocides with no toxic residuals, and they have been the subject of considerable interest $(3,16)$. HPPA mixtures are available commercially as general disinfectants for use in greenhouses, nurseries, postharvest handling of fruit, and other applications (13). Both components of HPPA have antimicrobial activity and are active against a wide range of organisms, including bacteria, fungi, and viruses (3). Hydrogen peroxide has been applied as a vapor or wash treatment to fresh fruit and vegetables $(11,21)$. Peroxyacetic acid is a more potent antimicrobial agent than hydrogen peroxide. Its activity is less affected by $\mathrm{pH}$ than that of many other disinfectants and, unlike chlorine, peroxyacetic acid remains effective in the presence of organic material (3). Still, chlorine and HPPA are oxidizers that are not highly effective in disinfecting inoculated, wounded fruit tissue and are deactivated by reducing agents (1).

The effect of chlorine on the viability of conidia of $P$. digitatum has been studied previously and exposures of $10 \mathrm{~s}$ in solutions of $100 \mathrm{mg} / \mathrm{liter}$ at $\mathrm{pH} 7$ inhibited conidial germination completely $(4,24)$. Although, in our studies, both sanitizers killed conidia of $P$. digitatum effectively, longer exposure times and much higher rates were required for HPPA (hydrogen peroxide at $2,700 \mathrm{mg} / \mathrm{liter}$ ) than for free chlorine $(50 \mathrm{mg} / \mathrm{liter})$. The activity of both sanitizers was higher at $\mathrm{pH} 6$ than 8 . For chlorine, at $\mathrm{pH} \mathrm{11,} \mathrm{conidia} \mathrm{of} P$. digitatum were not killed even when exposed to $1,000 \mathrm{mg} / \mathrm{liter}$ (4). This is due to the fact that, at higher $\mathrm{pH}$, hypochlorous acid dissociates to hypochlorite ions that are less active than hypochlorous acid $(8,30)$.

At 2,700 $\mathrm{mg}$ of hydrogen peroxide per liter, the use of HPPA can be economical. Additionally, if used in recirculating systems, long exposure times can be maintained considering that commercial fungicide reservoirs for in-line drenches contain up to 350 liters of solution that is being recirculated. The treatment system, flow rate, and reservoir size will determine the duration of contact time of the sanitizer. Thus, chlorine and HPPA can be effective for the sanitation of solutions. Still, if sanitation of a particular fungicide is needed, the use of chlorine may not be an option. For example, imazalil is incompatible with chlorine, resulting in reactions that diminish its antifungal activity (25); consequently, heat treatment or filtration is used for sanitation (26). This incompatibility was confirmed in our fungicide residue analyses and fruit treatments. Fungicide residues were not measured for azoxystrobin because the analytical lab that 
processed our samples was not equipped for the procedure. Furthermore, we demonstrated that pyrimethanil also was not stable in the presence of chlorine. Thus, only azoxystrobin and fludioxonil were stable in solutions that contained chlorine. All fungicides evaluated, however, were compatible with HPPA because fungicide residues and fungicide efficacy using mixtures with HPPA were similar to the use of the fungicides by themselves. Low rates of fungicides were used in the efficacy studies with fungicide-sanitizer mixtures. This resulted in higher incidences of fruit decay than with the planned label rates; however, any changes in fungicide efficacy due to the interaction with the sanitizers were more easily detected.

Smilanick et al. (28) reported that hydrogen peroxide at rates of 5,000 to 15,000 $\mathrm{mg} / \mathrm{liter}$ during 90 -s immersions at $25^{\circ} \mathrm{C}$ caused unacceptable injuries on lemon fruit. In our studies, no phytotoxic effects were evident after treatments with HPPA at $2,700 \mathrm{mg} / \mathrm{liter}$. Rind injuries were observed only when droplets of mixtures of azoxystrobin (1,000 mg/liter), free chlorine (100 mg/liter), and SBC (3\%) were left on the fruit during incubation (data not shown). Thus, HPPA offers an alternative sanitation treatment that could be used successfully in packinghouses. HPPA would be the sanitizer of choice for pyrimethanil and imazalil when recirculating fungicide systems are used. With azoxystrobin, fludioxonil, and TBZ, chlorine or HPPA could be used in recirculating systems even in mixtures with SBC, although chlorine was more effective at low concentrations, short exposure times, and higher $\mathrm{pH}$ levels.

The use of the alkaline buffers like carbonate and bicarbonate salts has been widely demonstrated to control a variety of postharvest pathogens of citrus $(1,9,18,32)$. In California, their beneficial action to reduce the incidence of Penicillium decays of citrus fruit has been suggested over 70 years ago $(9,17)$. The standard practice in citrus packinghouses is to wash and treat the fruit by immersing in a solution of 3 to $4 \%$ sodium carbonate or $\mathrm{SBC}$ at 40 to $46^{\circ} \mathrm{C}$ for 2 to $4 \mathrm{~min}$, followed by a freshwater rinse $(9,29)$. The sole use of these materials has its limitations in the control of postharvest decays; however, their mixture with fungicides can provide results superior to the individual treatments (29). In our laboratory studies, the addition of SBC significantly improved the performance of all three new postharvest fungicides, and similar results were reported by Smilanick et al. (26) for pyrimethanil. In the packingline studies, the efficacy of fludioxonil but not azoxystrobin also was improved significantly by the addition of SBC. The evaluated rate of azoxystrobin at $500 \mathrm{mg} / \mathrm{liter}$ was highly efficacious by itself in drench applications 14 to $16 \mathrm{~h}$ after fruit inoculation. Furthermore, adding chlorine to the fungicide-SBC mixtures had no effect on efficacy. SBC-chlorine mixtures also did not adversely influence the stability of fludioxonil and TBZ but had a negative effect on pyrimethanil and imazalil.

We previously demonstrated that, for optimum fungicide efficacy, azoxystrobin

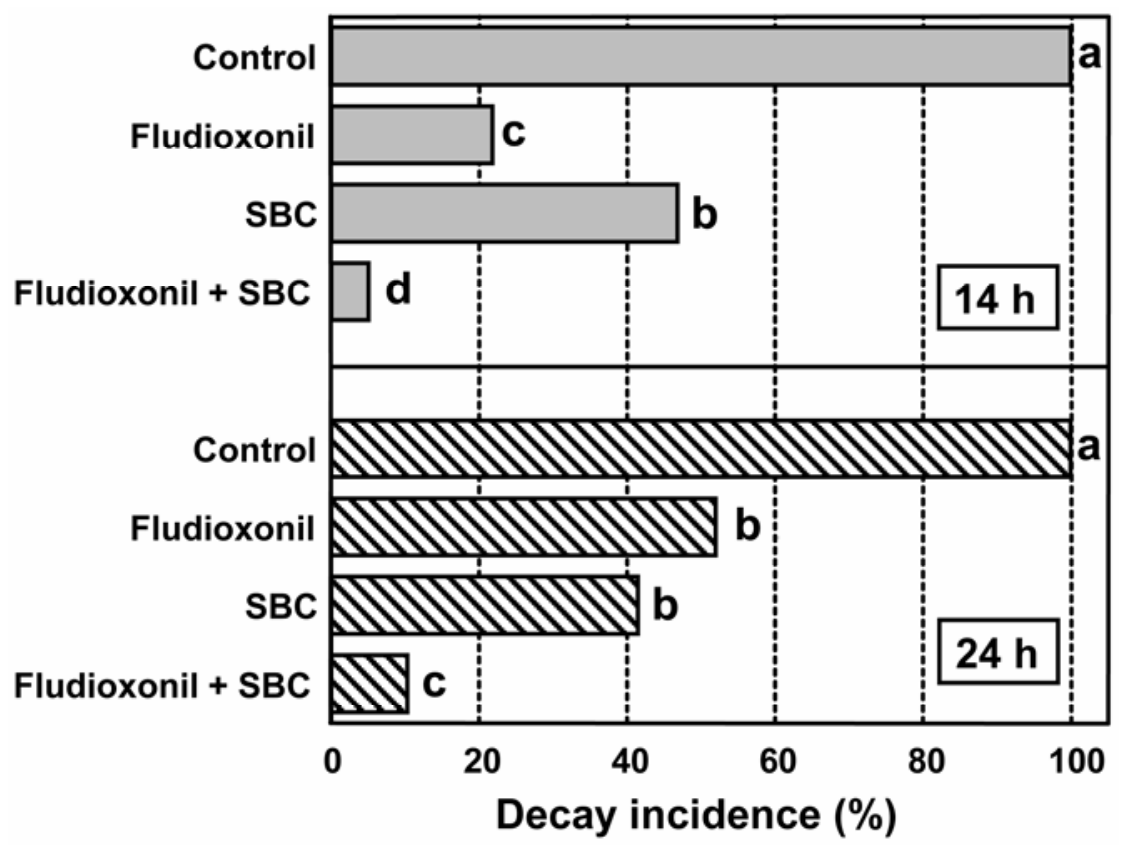

Fig. 5. Effect of sodium bicarbonate (SBC) on the efficacy of fludioxonil against green mold of lemon fruit in laboratory studies. Inoculated fruit were treated with fludioxonil at $300 \mathrm{mg} / \mathrm{liter}, 3 \%$ (wt/vol) SBC, or mixtures of fludioxonil and SBC after 14 or $24 \mathrm{~h}$. For each timing, horizontal bars with the same letter indicate that treatment means were not significantly different $(P<0.05)$ following an analysis of variance and least significant difference mean separation test procedures.
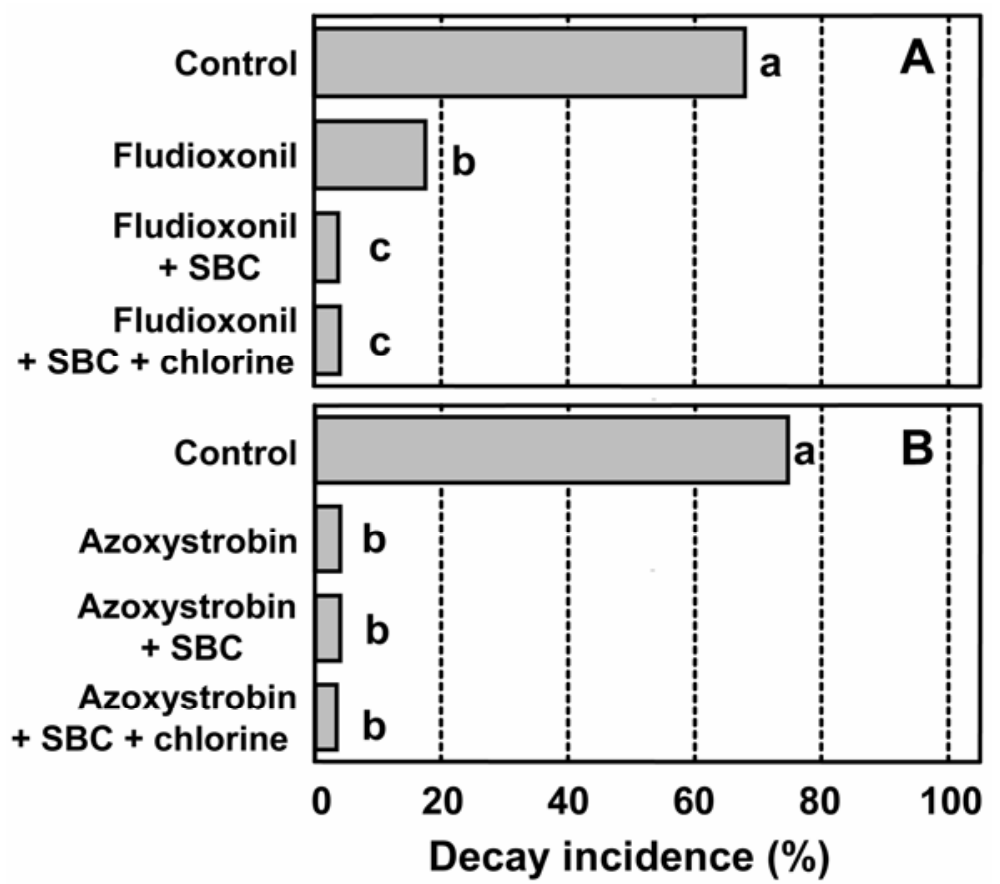

Fig. 6. Effect of sodium bicarbonate (SBC) and chlorine on the efficacy of azoxystrobin and fludioxonil against green mold of lemon fruit in experimental packingline studies. Inoculated fruit were treated after 14 to $16 \mathrm{~h}$ using high-volume, in-line drenches with azoxystrobin at $500 \mathrm{mg} / \mathrm{liter}$, fludioxonil at $300 \mathrm{mg} / \mathrm{liter}$, or mixtures of each of the two fungicides with $3 \%$ (wt/vol) SBC and free chlorine at $100 \mathrm{mg} / \mathrm{liter}$. A, For fludioxonil, treatment solutions were either nonheated $\left(25^{\circ} \mathrm{C}\right)$ or heated $\left(50^{\circ} \mathrm{C}\right)$ whereas $\mathbf{B}$, for azoxystrobin, only nonheated solutions were used. For fludioxonil, there was no significant interaction between nonheated and heated treatments and data were combined. For each fungicide, horizontal bars with the same letter indicate that treatment means were not significantly different $(P<0.05)$ following an analysis of variance and least significant difference mean separation test procedures. 
and fludioxonil should be applied within 12 to $15 \mathrm{~h}$ after inoculation of fruit (15). In the current study, mixtures of fludioxonil with SBC, however, were still highly effective when applied $24 \mathrm{~h}$ after inoculation. Thus, although the effect of SBC is fungistatic rather than fungicidal and SBC does not suppress subsequent sporulation on decayed fruit, it is an effective tool in integrated disease management programs $(18,28)$. Considering that the majority of fruit infections occur at harvest and that fruit often receive fungicide treatments between 18 and $24 \mathrm{~h}$ after harvest, the addition of SBC in the use of the new postharvest fungicides will be an important strategy thereafter. Additional benefits of using SBC on citrus include the partial control of fungicide-resistant strains of $P$. digitatum and of sour rot caused by Geotrichum citri-aurantii $(1,9)$.

Heated fungicide treatments are recognized as another strategy to reduce postharvest losses of citrus fruit (22). For TBZ and imazalil, applications at $50^{\circ} \mathrm{C}$ resulted in residues on fruit 2.5 and 8 times higher, respectively, than treatments at $20^{\circ} \mathrm{C}(6)$. Similar results were observed with heated aqueous solutions of azoxystrobin, fludioxonil, or pyrimethanil $(7,22,23,26)$. The increase in residues, however, did not always result in increased efficacy against citrus green mold. Thus, heated solutions that contained low rates (50 to 100 $\mathrm{mg} / \mathrm{liter}$ ) of the fungicides improved effectiveness in the control of green mold of lemon and orange fruit and residues were increased several-fold $(6,23,27)$. In these studies, however, no differences between temperatures were found when higher fungicide rates were used because high rates alone were effective. In our study, the application of heated $\left(50^{\circ} \mathrm{C}\right)$ solutions of fludioxonil at $300 \mathrm{mg} / \mathrm{liter}$ also did not affect efficacy compared with nonheated $\left(25^{\circ} \mathrm{C}\right)$ solutions, possibly due to the short exposure times in the drench application method that we used. Thus, the use of heated fludioxonil treatments for citrus at labeled rates is unlikely to be a strategy for improving fungicide efficacy in a recirculating, in-line drenching system. Furthermore, because low rates of fludioxonil might select for a stepwise increase in fungicide resistance in $P$. digitatum (14), fludioxonil should be used only at labeled rates in either heated or nonheated solutions. However, because the evaluated fungicides are stable at temperatures used in heated fruit treatment solutions $(23,25)$, they could be applied together with SBC in selected application systems.

The use of heat possibly could be used as an alternative method to sanitize recirculating treatment solutions. In one study, conidia of $P$. digitatum were killed in 15-s exposures at $59^{\circ} \mathrm{C}$ (19); however, in another study, conidia of $P$. digitatum and other citrus postharvest pathogens were not inactivated by 30 -s exposures at $50^{\circ} \mathrm{C}$
(30). Treatments of inoculated fruit for 150 $\mathrm{s}$ with water at $45^{\circ} \mathrm{C}$ have been shown to decrease significantly the incidence of green mold (28). Thus, because long contact times can be provided in recirculated solutions, pathogen propagules may be effectively inactivated when using heated solutions in drench treatments. Still, the heating of solutions may not be costeffective compared with the use of a sanitizing agent.

In this study, we investigated strategies to improve the efficacy of new postharvest fungicides against green mold. Some of these strategies, such as application method and the interaction with SBC or HPPA, resulted in a similar response for all fungicides, whereas others, such as the interaction with chlorine, varied among fungicides. Previously, we reported on the efficacy of azoxystrobin, fludioxonil, and pyrimethanil as single and mixture treatments for decay and sporulation control, as well on fungicide compatibility with postharvest fruit coatings (15). Based on this information, usage strategies that would lead to the most effective and economic decay control while also providing tools for sound sanitation practices can be designed. In addition, some information also could be applicable to other fruit systems such as pome fruit that currently are often bin or truck drenched. Due to the common occurrence of fungicide resistance in $P$. digitatum populations, and because a limited number of postharvest fungicides is registered on citrus, all available tools have to be utilized in an integrated management system to minimize fruit losses and prolong fungicide efficacy while minimizing the selection for resistant populations of the pathogen.

\section{ACKNOWLEDGMENTS}

This research was supported financially by the Citrus Research Board of California, and is part of a Ph.D. dissertation of Loukas Kanetis. We thank Janssen Pharmaceutica Inc., Bayer Crop Science, and Syngenta Crop Protection for their technical and financial contributions; S. Wartanessian from Decco-Cerexagri for conducting gas chromatography residue analyses; and G. Driever for assistance during the experimental packingline experiments at the University of California, Kearney Agricultural Center.

\section{LITERATURE CITED}

1. Adaskaveg, J. E., Förster, H., and Sommer, N. F. 2002. Principles of postharvest pathology and management of decays of edible horticultural crops. Pages 163-195 in: Postharvest Technology of Horticultural Crops. A. A. Kader, ed. University of California, Division of Agricultural and Natural Resources, Publ. no. 3311, Oakland, CA.

2. Adaskaveg, J. E., Kanetis, L., Soto-Estrada, A., and Förster, H. 2004. A new era of postharvest decay control in citrus with the simultaneous introduction of three new "reduced-risk" fungicides. Pages 999-1004 in: Proc. Int. Soc. Citricult.

3. Block, S. S. 2001. Peroxygen compounds. Pages 185-204 in: Disinfection, Sterilization and Preservation, 5th ed. S. S. Block, ed. Lippincott Williams and Wilkins, Philadelphia, PA.
4. Brown, G. E., and Wardowski, W. F. 1984. Use of chlorine and chlorine dioxide in Florida citrus packinghouses to reduce inoculum of decay pathogens. Proc. Fla. State Hortic. Soc. 97:97-100.

5. Bus, V. G., Bongers, A. J., and Risse, L. A. 1991. Occurrence of Penicillium digitatum and P. italicum resistant to benomyl, thiabendazole, and imazalil on citrus fruit from different geographical origins. Plant Dis. 75:1098-1100.

6. Cabras, P., Schirra, M., Pirisi, F. P., Garau, V. L., and Angioni, A. 1999. Factors affecting imazalil and thiabendazole uptake and persistence in citrus fruits following dip treatments. J. Agric. Food Chem. 47:3352-3354.

7. D’Aquino, S., Schirra, M., Palma, A., Angioni, A., Cabras, P., and Migheli, Q. 2006. Residue level and effectiveness of pyrimethanil vs imazalil when using heated postharvest treatments for control of Penicillium decay on citrus fruit. J. Agric. Food Chem. 54:4721-4726.

8. Dychdala, G. R. 2001. Chlorine and chlorine compounds. Pages 135-157 in: Disinfection, Sterilization and Preservation, 5th ed. S. S. Block, ed. Lippincott Williams and Wilkins, Philadelphia, PA.

9. Eckert, J. W., and Eaks, I. L. 1989. Postharvest disorders and diseases of citrus fruit. Pages 179-260 in: The Citrus Industry, Volume V. W. Reuter, E. C. Calavan, and G. E. Carman, eds. University of California, Division of Agricultural and Natural Resources, Publ. no. 3326, Oakland, CA.

10. Eckert, J. W., and Wild, B. L. 1983. Problems of fungicide in Penicillium rot of citrus fruit. Pages 525-556 in: Pest Resistance to Pesticides. G. P. Georghiou, and T. Saito, eds. Plenum Publishing Corp., New York.

11. Forney, C. F., Rij, R. E., Denis-Arrue, R., and Smilanick, J. L. 1991. Vapor phase hydrogen peroxide inhibits postharvest decay of table grapes. HortScience 26:1512-1514.

12. Förster, H., Driever, G. F., Thompson, D. C., and Adaskaveg, J. E. 2007. Postharvest decay management for stone fruit crops in California using the "reduced-risk" fungicides fludioxonil and fenhexamid. Plant Dis. 91:209-215.

13. Jagdale, G. B., and Grewal, P. S. 2002. Identification of alternatives for management of foliar nematodes in floriculture. Pest Manag. Sci. 58:451-458.

14. Kanetis L., Förster, H., and Adaskaveg, J. E. 2006. Fludioxonil-resistant isolates of Penicillium digitatum show diverse fitness and no relationship to osmotic stress regulation. (Abstr.) Phytopathology 95:S58.

15. Kanetis L., Förster, H., and Adaskaveg, J. E. 2007. Comparative efficacy of the new postharvest fungicides azoxystrobin, fludioxonil, and pyrimethanil for managing citrus green mold. Plant Dis. 91:1502-1511.

16. Mari, M., Cembali, T., Baraldi, E., and Casalini, L. 1999. Peracetic acid and chlorine dioxide for postharvest control of Monilinia laxa in stone fruits. Plant Dis. 83:773-776.

17. Marloth, R. H. 1931. The influence of hydrogen-ion concentration and of sodium bicarbonate and related substances on Penicillium italicum and $P$. digitatum. Phytopathology 21:169:198

18. Palou, L., Smilanick, J. L., Usall, J., and Vinas, I. 2001. Control of postharvest blue and green molds of oranges by hot water, sodium carbonate, and sodium bicarbonate. Plant Dis. 85:371-376.

19. Porat, R., Daus, A., Weiss, B., Cohen, L. Fallik, E., and Droby, S. 2000. Reduction of postharvest decay in organic citrus fruit by a short hot water brushing treatment. Postharvest Biol. Technol. 18:151-157.

20. Roberts, R. G., and Reymond, S. T. 1994. Chlorine dioxide for reduction of postharvest pathogen inoculum during handling of tree fruits. Appl. Environ. Microbiol. 60:2864-2868. 
21. Sapers, G. M., and Simmons, G. F. 1998. Hydrogen peroxide disinfection of minimally processed fruits and vegetables. Food Technol. 52:48-52.

22. Schirra, M., Cabras, P., Angioni, A., and Brandolini, V. 2002. Residue levels and storage decay control in cv. Star Ruby grapefruit after dip treatments with azoxystrobin. J. Agric. Food Chem. 50:1461-1464.

23. Schirra, M., D’Aquino, S., Palma, A., Marceddu, S., Angioni, A., Cabras, P., Scherm, B., and Migheli. Q. 2005. Residue level, persistence, and storage performance of citrus fruit treated with fludioxonil. J. Agric. Food Chem. 53:6718-6724.

24. Smilanick, J. L., Aiyabei, J., Mlikota Gabler, F., Doctor, J., Sorenson, D., and Mackey, B. 2002. Quantification of the toxicity of aqueous chlorine to spores of Penicillium digitatum and Geotrichum citri-aurantii. Plant Dis. 86:509514.
25. Smilanick, J. L., Mansour, M. F., Margosan, D. A., Mlikota Gabler, F., and Goodwine, W. R. 2005. Influence of $\mathrm{pH}$ and $\mathrm{NaHCO}_{3}$ on effectiveness of imazalil to inhibit germination of Penicillium digitatum and to control postharvest green mold on citrus fruit. Plant Dis. 89:640-648.

26. Smilanick, J. L., Mansour, M. F., Mlikota Gabler, F., and Goodwine, W. R. 2006. The effectiveness of pyrimethanil to inhibit germination of Penicillium digitatum and to control citrus green mold after harvest. Postharvest Biol. Technol. 42:75-85.

27. Smilanick, J. L., Mansour, M. F., and Sorenson, D. 2005. Pre- and postharvest treatments to control green mold of citrus during ethylene degreening. Plant Dis. 90:8996.

28. Smilanick, J. L., Margosan, D. A., and Henson, D. J. 1995. Evaluation of heated solutions of sulfur dioxide, ethanol, and hydrogen peroxide to control postharvest green mold of lemons. Plant Dis. 79:742-747.

29. Smilanick, J. L., Margosan, D. A., Mlikota, F., Usall, J., and Michael, I. F. 1999. Control of citrus green mold by carbonate and bicarbonate salts and the influence of commercial postharvest practices on their efficacy. Plant Dis. 83:139:145.

30. Smilanick, J. L., Sorenson, D., Mansour, M. F., Aiyabei, J., and Plaza, P. 2003. Impact of a brief postharvest hot water drench treatment on decay, fruit appearance, and microbe populations of California lemons and oranges. HortTechnology 13:333-338.

31. White, G. C. 1999. Handbook of Chlorination and Alternative Disinfectants, 4th ed. J. Wiley \& Sons, New York.

32. Zhang, J., and Swingle, P. 2004. Control of green mold on Florida citrus fruit using bicarbonate salts. Proc. Fla. State Hortic. Soc. 116:375-378 